\title{
APPLICATION OF SOFT RELINING MATERIALS BY DENTISTS - A PILOT STUDY
}

\author{
Ilian Hristov, Diyan Slavchev, Dobromira Shopova, Lyubomir Grozev, Bozhana \\ Chuchulska \\ Department of prosthetic dentistry, Faculty of Dental Medicine, Medical \\ University - Plovdiv, Bulgaria.
}

\begin{abstract}
:
Purpose: The aim of this study is to analyse the dentists' awareness of the soft relining materials - their behaviour, advantages and disadvantages.

Materials and methods: A direct survey method was applied, as well as a documentary method of gathering statistical information. For the purpose of this investigation, a standard questionnaire has been presented, consisting of seven questions each.

Results: The age group have no influence on the frequency of use of soft relining materials in practice. According to $49.57 \%$ of the interviewed dentists, the most frequently observed disadvantage is the hardening of these materials in a very short notice. Staining from food and beverage and frequently noticed bond failure from the denture basis were also observed, $18,26 \%$ consider discoloration from disinfectants a problem as well. The majority of the interviewed $(56,52 \%)$ have been answered, that their patients are pleased from the applied SRM. 70,43\% have been answered that SRM matches the denture basis and the rest $29,57 \%$ have been pointed out that these materials are not very aesthetic.
\end{abstract}

Discussion: Although the majority of the dentists declare, that they are aware of the properties of the soft relining materials, they are a little bit sceptical about their use in practice. On the other hand, the patients are satisfied and find them very useful and beneficial.

Conclusion: It can be concluded, that the majority of the dentists are very well acquainted with the soft relining materials, their purpose and way of application.

Keywords: survey, inquiry method, soft relining materials.

\section{BACKGROUND:}

Nowadays there are three possible options for overcoming problems connected with the functional stability of total dentures, using:

o Implants

o Dental adhesives

o Soft relining materials

The third method is probably the least possibly known and used by the practitioners. The soft relining materials can help overcoming problems with retentional al- veolar ridges, undercuts, painful zones, cases with xerostomia, thin mucosis, etc. These materials with their cushioning effect can distribute the masticatory forces more evenly and thus prevent the alveolar ridges from quick resorption.

\section{PURPOSE:}

To analyse the dentists' awareness of the soft relining materials - their behaviour, advantages and disadvantages.

\section{MATERIALS AND METHODS:}

A direct survey method was applied, as well as a documentary method of gathering statistical information.

For the purpose of this investigation a standard questionnaire has been presented, consisting of seven questions each, considering:

- gender

- age

- what the SRM act for

- their use in practice

- adverse properties

- patients' opinion

- aesthetic estimation

The research was held during the congresses and meetings, organised by the BDU. The inquiry was realised from March - October 2015.

A direct inquiry method was used. The inquired dentists answered in written form the submitted questions, arranged in questionnaires, for gathering primary empirical data about their attitude towards the investigated problem. The received answers were kept anonymous.

\section{RESULTS:}

One hundred and fifteen dentists were questioned (evenly distributed by gender), covering all professionally active ages. It became evident that, that $2 / 3$ of the questioned dentists were very well acquainted with the properties of the soft relining materials, 1/3 declared, that they have heard about them without having enough detailed information and $1.74 \%$ - did not have any idea about these group of products.

There are no significant differences in the degree of awareness in the different age groups. This has been illus- 
trated by the graphs in chart 1 and has been confirmed by the Pierson's $\chi^{2}$-criteria.

Chart 1: Awareness of soft relining materials, by age groups

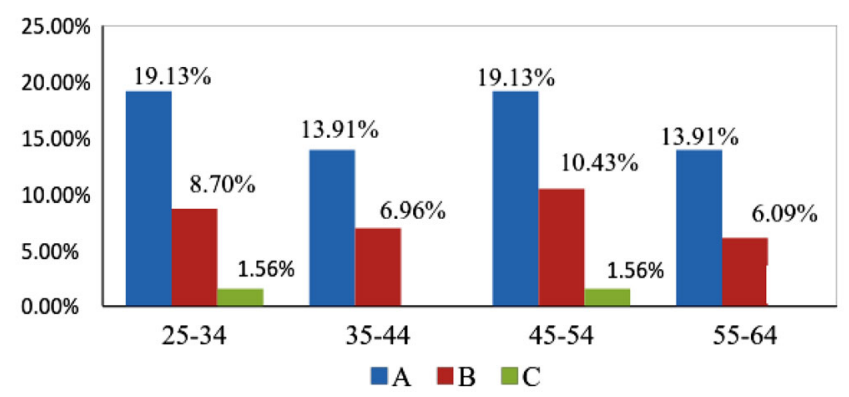

We have used $\chi^{2}$-criteria for independence for verification the null hypothesis against its alternative.

Analysis of the frequency distribution was done by IBM SPSS STATISTICS (ver. 19). (table1)

Table 1: Analysis of the frequency distribution of the awareness of the questioned groups*

\begin{tabular}{|l|ccc|c|}
\cline { 2 - 4 } \multicolumn{1}{c|}{} & \multicolumn{3}{c|}{ Observed frequencies $\mathrm{n}_{\mathrm{ij}}$} & \multicolumn{1}{c}{} \\
\hline Awareness & $\mathrm{A}$ & $\mathrm{B}$ & $\mathrm{C}$ & Total \\
\hline $25-34 \mathrm{y}$ & 22 & 10 & 1 & 33 \\
$35-44 \mathrm{y}$ & 16 & 8 & 0 & 24 \\
$45-54 \mathrm{y}$ & 22 & 12 & 1 & 35 \\
$55-64 \mathrm{y}$ & 16 & 7 & 0 & 23 \\
\hline Total & 76 & 37 & 2 & 115 \\
\hline
\end{tabular}

*A. Yes, I am aware of them; B. I've heard about them, but I don't know any details; C. I have no idea,

The received result of the empiric value $\chi^{2}$ emp., which gives information about the difference between the observed and expected theoretical frequencies is $\chi_{\text {emp }}^{2}=1,60$. In degree of freedom (3-1).(4-1) $=6$, this value of $\chi^{2}$ emp. responds to $\mathrm{p}$ (value) $=0,95$. There is no reason to reject the null hypothesis and has been accepted that the degree of awareness does not depend on the age group.

The question: "Do you use often soft relining materials in your private practice?" was answered by

- 46,09\% with "YES."

- 53,91\% with "No" (chart 2)
Chart 2: Use of soft relining materials by age groups and table 2: Analysis of frequency distribution

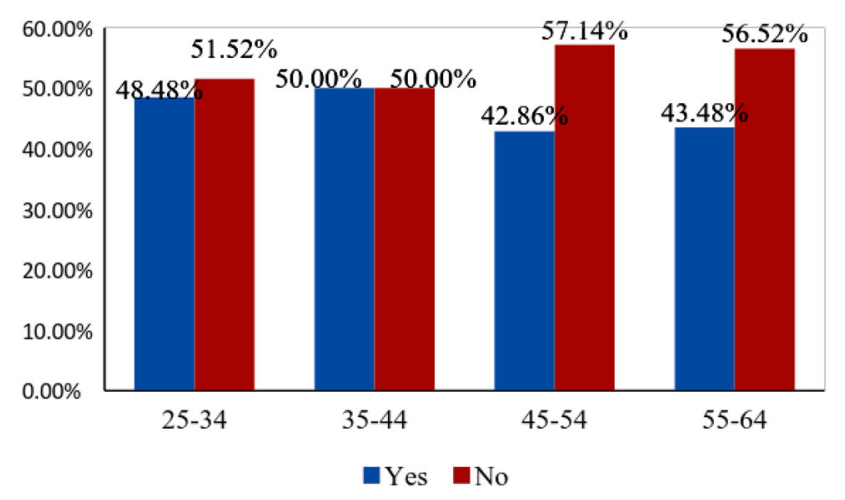

Tabl. 2. Analysis of frequency distribution:

\begin{tabular}{|l|cc|c|}
\cline { 2 - 4 } \multicolumn{1}{c|}{} & \multicolumn{3}{c|}{ Observed frequencies $\mathrm{n}_{\mathrm{ij}}$} \\
\hline Use & Yes & No & Total \\
\hline $25-34 \mathrm{y}$. & 16 & 17 & 33 \\
$35-44 \mathrm{y.}$ & 12 & 12 & 24 \\
$45-54 \mathrm{y}$. & 15 & 20 & 35 \\
$55-64 \mathrm{y}$. & 10 & 13 & 23 \\
\hline Total & 53 & 62 & 115 \\
\hline
\end{tabular}

Using the data from table 2 through IBM SPSS STATISTICS (ver. 19), we checked the null and alternative hypothesis:

The received result of the empiric value $\chi^{2}$ emp., which gives information about the difference between the observed and expected theoretical frequencies is $\chi_{\text {emp }}^{2}=0,43$. In degree of freedom (2-1). (4-1) $=3$, this value of $\chi^{2}$ emp. responds to $\mathrm{p}$ (value) $=0,95$. There is no reason to reject the null hypothesis and has been accepted that the age group have no influence on the frequency of use of soft relining materials.

Answering the fifth question of the quest, the dentists were supposed to point out the observed unfavourable properties of the SRM. According to $49.57 \%$ of the interviewed dentists, the most frequently observed disadvantage is the hardening of these materials in a very short notice $[1,2,3]$. In this case, they are losing their best property softness, and that makes them useless. Staining from food and beverage $(40 \%)[4,5,6,7]$ and frequently noticed bond failure $[8,9,10,11]$ from the denture basis $(36.52 \%)$ were also observed. 18,26\% consider discoloration from disinfectants a problem $[12,13,14]$. (chart3) 
Chart 3: Observed unfavourable properties

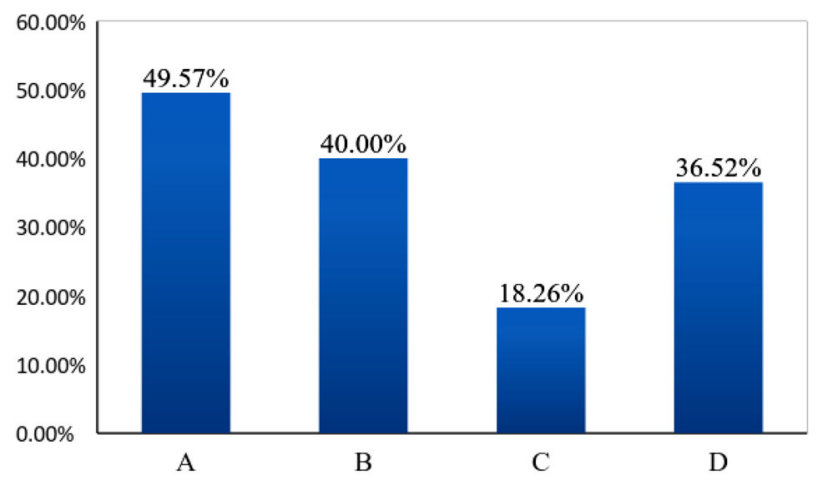

A. They are getting hard very quickly; B. Staining from food and beverage; C. Discoloration from disinfectants; D. Bond failure from the denture basis

The majority of the interviewed $(56,52 \%)$ have been answered, that their patients are pleased from the applied SRM because they don't feel pain any more and they don't have any mucosal injuries. $48,70 \%$ estimate the better stability of the dentures. Only 13,04\% answered that they don't see any substantial difference when applying SRM (chart 4).

Chart 4: Patients' opinion about the SRM

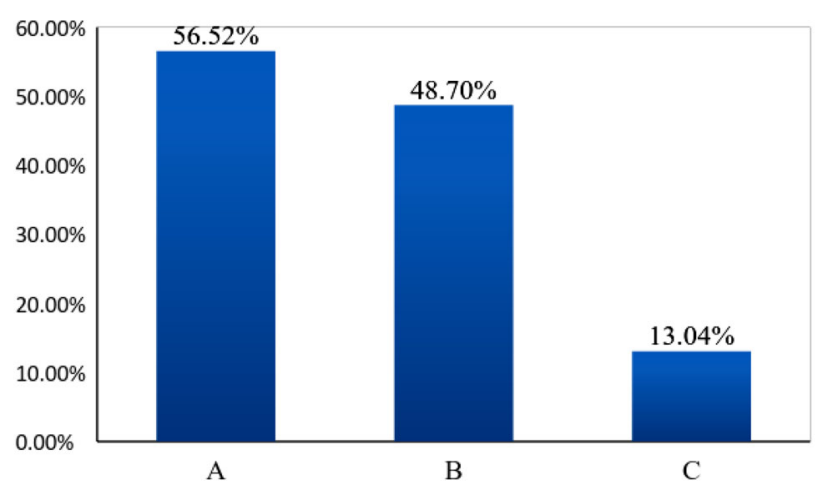

A. They are completely satisfied; B. The stability of the dentures is better; $\mathrm{C}$. There is no difference

The last question from the quest was about the evaluation of SRM from an aesthetic point of view. 70,43\% have been answered that SRM matches the denture basis and the rest $29,57 \%$ have been pointed out that these materials are not very aesthetic (chart 5).
Chart 5: Aesthetic estimation of SRM from all participants in the survey

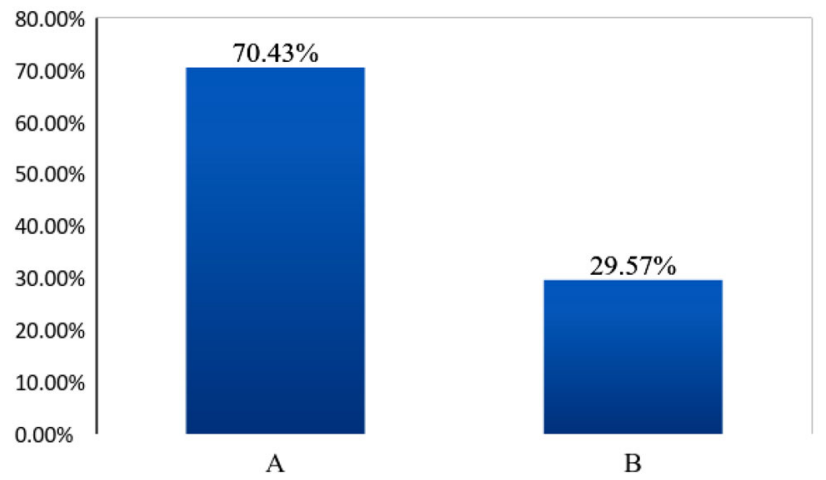

A. SRM match the denture basis; B. They are not very esthetic

From the graph of chart 6 can be proposed a connection between the aesthetic estimation of the interviewed dentists and their gender. It is evident from the chart that $83,05 \%$ of the women find the SRM been aesthetic and only $16,95 \%$ of them share the opposite opinion. As far as the men are considered they consider the SRM been aesthetic $57,14 \%$, against $42,86 \%$, who consider them not aesthetic (chart 6).

Chart 6: Aesthetic evaluation of the SRM by gender

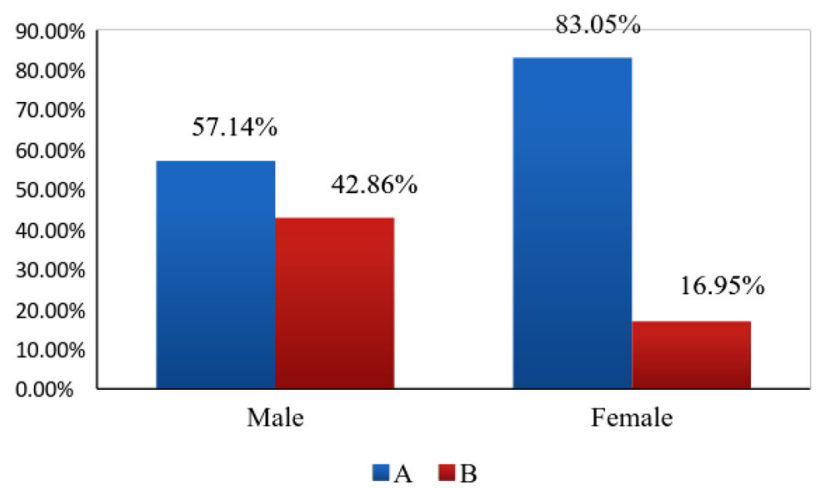

In order to check whether the gender has any influence over the aesthetic evaluation of the SRM, the computer program IBM SPSS STATISTICS (ver. 19) was used to check the null and alternative hypothesis. (table3) 
Table 3: Analysis of frequency distribution of aesthetic evaluation by gender

\begin{tabular}{|c|cc|c|}
\cline { 2 - 4 } \multicolumn{1}{c|}{} & \multicolumn{3}{c|}{ Observed frequencies $\mathrm{n}_{\mathrm{ij}}$} \\
\hline Aesthetic evaluation & $\mathrm{A}$ & $\mathrm{B}$ & Total \\
\hline Male & 32 & 24 & 56 \\
Female & 49 & 10 & 59 \\
\hline Total & 81 & 34 & 115 \\
\hline
\end{tabular}

Considering the $\chi^{2}$-criteria for independence and $\chi^{2}$ emp $=9,26$ and its responding $\mathrm{p}($ value $)=0,0023$, in degree of freedom (2-1).(2-1) = 1, the null hypothesis has been rejected, and its alternative is accepted. That means that gender does have an influence of the aesthetic evaluation of the soft relining materials.

\section{DISCUSSION:}

Although the majority of the dentists declare, that they are aware of the properties of the soft relining materials, they are a little bit sceptical about their use in practice. The observed disadvantages are: change of hardness, staining from food and beverage, bond failure, discoloration from disinfectants. Change of hardness is usually connected with plasticizers lost. The plasticizers leach into the oral cavity and easily swallowed by patients. We have to be very much aware of this phenomenon because these substances are made of phthalates and compounds are not harmless to the human organism, because they may cause dif- ferent disorders like fertile problems, cancer etc. Bond failure is considered to be a major problem especially in cases where the denture basis is made of acrylic, and the SRM is silicone. Obviously, between these two totally different materials, there is no chemical bond, that's why the manufacturers supply these products with relevant adhesives. It is advisable if there is no original adhesive in the package, a proper analogue to be found. On the other hand, the patients are satisfied and find them very useful and beneficial. The dental practitioner has to decide himself, which is the proper clinical case for using SRM.

\section{CONCLUSION:}

It can be concluded, that the majority of the dentists are very well acquainted with the soft relining materials, their purpose and way of application in clinics. They are aware of the disadvantages of these materials as well. Most of the interviewed specialists consider them aesthetic and declare that their patients find the properties of the materials quite good.

\section{Abbreviations: \\ SRM - Soft relining materials \\ BDU - Bulgarian Dental Union}

\section{Acknowledgements:}

This investigation was partially supported by University Grant - DP-06/2013 of Medical University Plovdiv.

\section{REFERENCES:}

1. Gurdal P, Akdeniz BG, Hakan Sen B. The effects of mouth rinses on microhardness and color stability of esthetic restorative materials. J Oral Rehabil. 2002 Sep;29 (9):895- 901. [PubMed]

2. Gürgan S, Onen A, Köprülü H. In vitro effects of alcohol- containing and alcohol free mouth rinses on microhardness of some restorative materials. J Oral Rehabil. 1997 Mar; 24(3):244-6. [PubMed]

3. Jadhav V, Shetty MM, Kalavathy N, Kumar R. Effect of 3 types of antifungal agents on hardness of 2 different commercially available tissue conditioners: An in-vitro study. SRM J Res Dent Sci. 2013; 4(4):150-3. [CrossRef]

4. Büyükerkmen E, Çelebi H, Akin C. Effect of different solutions on color stability of different denture base materials. Abstract book. 21st BaSS Congress. May 2016.

5. Canay S, Hersek N, Tulunoglu I, Uzun G. Evaluation of colour and hard- ness changes of soft lining materials in food colorant solutions. J Oral Rehabil. 1999 Oct;26(10):821-9. [PubMed] [CrossRef]

6. Goiato MC, Zuccolotti BC, Moreno A, dos Santos DM, Pesqueira AA, Dekon SF. Colour change of soft denture liners after storage in coffee and coke. Gerodontology. 2011 Jun; 28(2):140-5. [PubMed] [CrossRef]

7. Jin C, Nikawa H, Makihira S, Hamada T, Furukawa M, Murata H. Changes in surface roughness and colour stability of soft denture lining materials caused by denture cleansers. $J$ Oral Rehabil. 2003 Feb;30(2):125-30. [PubMed] [CrossRef]

8. Akin H, Tugut F, Mutaf B, Akin G, Ozdemir AK. Effect of different surface treatments on tensile bond strength of silicone-based soft denture liner. Lasers Med Sci. 2011 Nov;26(6): 783-8. [PubMed] [CrossRef]

9. Akin H, Tugut F, Guney U, Kirmali O, Akar T. Tensile bond strength of silicone-based soft denture liner to two chemically different denture base resins after various surface treatments. Lasers Med Sci. 2013 Jan; 28(1):119-23. [PubMed] [CrossRef]

10. Emmer TJ Jr, Emmer TJ Sr, Vaidynathan J, Vaidynathan TK. Bond strength of permanent soft denture liners bonded to the denture base. J Prosthet Dent. 1995 Dec;74(6):595601. [PubMed]

11. Rajaganesh N, Sabarinathan S, Azhagarasan NS, Shankar C, Krishnakumar J, Swathi S. Comparative evaluation of shear bond strength of two different chairside soft liners to heat processed acrylic denture base resin: An in vitro study. J Pharm Bioallied Sci. 2016 Oct;8(Suppl 1): S154-59. [PubMed] [CrossRef]

12. Davi LR, Peracini A, Ribeiro Nde Q, Soares RB, da Silva CH, Paranhos Hde F, et al. Effect of the physical properties of acrylic resin of overnight immersion in sodium hypochlorite solution. Gerodontology. 2010 Dec;27(4):297-302. [PubMed] 
[CrossRef]

13. de Freitas Fernandes FS, Pereira-Cenci T, da Silva WJ, Filho AP, Straioto FG, Del Bel Cury AA. Efficacy of denture cleansers on Candida spp. biofilm formed on polyamide and polymethyl methacrylate resins. $J$ Prosthet Dent. 2011 Jan;105(1):51-8.

\section{[PubMed] [CrossRef]}

14. Nordbö H, Attramadal A, Eriksen HM. Iron discoloration of acrylic resin exposed to chlorhexidine or tannic acid: a model study. $J$ Prosthet Dent. 1983 Jan;49(1):126-9. [PubMed]

Please cite this article as: Hristov I, Slavchev D, Shopova D, Grozev L, Chuchulska B. Application of soft relining materials by dentists - a pilot study. J of IMAB. 2017 Oct-Dec;23(4):1721-1725.

DOI: https://doi.org/10.5272/jimab.2017234.1721

Received: 14/05/2017; Published online: 26/10/2017

Address for correspondence:

Ilian Hristov - MSc, assistant-professor, PhD-candidate

Department of Prosthetic dentistry, FDM, Medical University - Plovdiv 3, Hristo Botev blvd., Plovdiv 4000, Bulgaria

E-mail: ilian.hristov@mail.bg 